\title{
Analysis of Antioxidants and its Properties of Vitamins as a Key Source for Human Health
}

\section{Vora Axita P, Mistry Parth R, Patel Prachi K, Gohel Payal K, Rathod Zalak R* and Saraf Meenu S}

Department of Microbiology and Biotechnology, University School of Sciences, Gujarat University, Gujarat, India

*Corresponding Author: Rathod Zalak R, Department of Microbiology and Biotechnology, University School of Sciences, Gujarat University, Gujarat, India.
Received: January 28, 2022

Published: February 24, 2022

(C) All rights are reserved by Rathod Zalak R., et al.

DOI: $10.31080 /$ ASNH.2022.06.1015

\begin{abstract}
Antioxidants are one of the most powerful safeguards for our long-term health; they work to protect our bodies from the damaging effects of chemicals and free radicals that humans may encounter through normal activities such as breathing or through environmental contaminants such as cigarette smoke or pollutants. Chronic diseases are exacerbated by oxidative stress. Increased antioxidant capacity in the body can help to minimise oxidative stress and prevent or alleviate disease. Some food components and/ or organism-produced vitamins, like vitamin C, E, A and carotenoids, are well-known antioxidants; however, other vitamins with antioxidant potential, such as Vitamin K, Vitamin D, Niacin, Pyridoxine, and Riboflavin, are rarely featured. This review includes studies that looked into the antioxidant properties of vitamins, as well as known antioxidants, and their impact on oxidative stress reduction. Further, other vitamins, according to the reviewed studies, have showed antioxidant properties and can help with oxidative stress, such as lipid peroxidation, protein carboxylation, and the reduction of advanced gyrated end-products.
\end{abstract}

Keywords: Antioxidant; Analysis; Free Radical; Oxidative Stress; Scavenging Activity; Vitamins

\section{Introduction}

Many chronic illnesses, such as cardiovascular disease [41], cancer, and diabetes [19], are caused by oxidative stress. Because these diseases are of public health concern, some researchers have focused their attention on the link between oxidative stress and them. One strategy to reduce oxidative stress is to increase antioxidant capacity. Many researches have looked at the antioxidant properties of vitamins such vitamin E, C, and Carotenoids, as well as their impact in human health. The antioxidant potential of the vitamins indicated above has practically become a well-established fact. Despite the fact that the involvement of other vitamins in oxidative stress has received less attention, these vitamins have not been adequately evaluated for their role as antioxidants in health or in their deficient condition. Vitamin K, Vitamin D, Niacin, Pyridoxine, and Riboflavin are some of the overlooked antioxidant vitamins. They serve as co-enzymes in many circumstances to combat free radicals, and their deficient levels can lead to oxidative stress. Vitamin K on neuroprotection, riboflavin on lipid peroxidation and protein carbonyls, and vitamin B12 on retinal ganglion cells [21] are only a few of the research that have been carried out on these vitamins. A lack of these vitamins has also been linked to oxidative stress-related disorders such as atherogenesis, as well as elevated homocysteine, which raises cardiovascular risk [37]. The examples given above demonstrate that these vitamins have antioxidant properties, although additional research into these vitamins is needed.

\section{Free radicals}

When oxygen interacts with specific compounds, free radicals are generated which are atoms or groups of atoms with an odd (unpaired) number of electrons. These are extremely reactive radicals, once produced, can set off a domino effect. In general, free radicals are members of the reactive oxygen species (ROS), reactive nitrogen species (RNS), and reactive sulphur species (RSS) molecular families (RSS). For example:

- ROS include:

- As superoxide anion $\left(\mathrm{O}_{2}{ }^{\circ}\right)$.

- $\quad$ Perhydroxyl radical $\left(\mathrm{HO}_{2}{ }^{\circ}\right)$.

- Hydroxyl radical $(\cdot \mathrm{OH})$

- $\quad$ Nitric oxide

- Other species such as hydrogen peroxide $\left(\mathrm{H}_{2} \mathrm{O}_{2}\right)$, singlet oxygen $\left({ }^{1} \mathrm{O}_{2}\right)$, hypochlorous acid $(\mathrm{HOCl})$ and peroxynitrite (ONOO-). 
- $\quad$ RNS are derived from nitric oxide through the reaction with $\mathrm{O}_{2}$ - to form ONOO.

- $\quad$ RSS are easily formed from thiols by reaction with ROS [32].

\section{Oxidative stress}

Oxidative stress is a situation that occurs when the body's free radical and antioxidant defence systems are out of balance. Free radicals and antioxidants are in equilibrium in healtly condition [3], but in oxidative stress condition, there are much more reactive oxygen and nitrogen species than antioxidants. The presence of unpaired electrons in valence orbitals makes some atoms unstable and extremely reactive. They achieve stability by stealing electrons from adjacent molecules in the body, resulting in a chain reaction that damages cells and causes illnesses [3]. This event causes the formation of peroxides and free radicals, which can harm nucleic acids, proteins, lipids, carbohydrates, and other molecules in the cell $[3,14]$. Superoxide radical, hydrogen peroxide $\left(\mathrm{H}_{2} \mathrm{O}_{2}\right)$, and hydroxyl radical are the two principal kinds of radicals or reactive oxygen species, whereas nitric oxide and its metabolites are the reactive nitrogen species [3]. Diabetes mellitus, renal failure, cardiovascular illnesses, cancer, polycystic ovary syndrome, and neurological disorders have all been linked to oxidative stress, according to studies [47]. Excess free radicals are neutralised by antioxidants. Endogenous antioxidants are created in the body, while exogenous antioxidants are obtained from nutrition (exogenous). Many studies have found a reduction in endogenous antioxidants in a variety of illness states. As a result, exogenous antioxidants must be included in the diet to counteract the harmful effects of diminished antioxidants and increased free radicals in disease states.

\section{Vitamins}

Vitamins are complex chemical molecules present in meals and/or organisms that are necessary for proper metabolism. Their insufficiency might cause problems, although resupplying these nutrients can help ease the symptoms of deficiency. Vitamins vary from other food nutrients in that they are organic, and their classification is based on their chemical nature and function [46]. Vitamins are required in minute amounts for growth, development, health, and reproduction. Some vitamins that are synthesised in the body from other sources stray from the traditional concept of vitamins. Animals, for example, combine ascorbic acid, tryptophan, an important amino acid, to generate niacin, while vitamin D is synthesised by UV radiation from sunshine.

Vitamins can be divided into two categories in general:

- Water soluble

- Fat soluble
Water-soluble vitamins include vitamins $\mathrm{B}$ complex and $\mathrm{C}$, whereas fat-soluble vitamins include vitamins A, D, E, and K. Fatsoluble vitamins are linked to fats and are absorbed in the presence of fats in the diet. Fat-soluble vitamins are absorbed in the same way that fats are. Water-soluble vitamins are unaffected by changes in fat absorption and are not related to fats. Vitamin A is a fat-soluble vitamin that can be found in both plants and animals. Retinoids are vitamin A derived from animal sources, whereas provitamin A carotenoids are vitamin A derived from plant sources [23]. They are required for eyesight, cell growth and development, antioxidant action, and cell communication.

Vitamin D is essential for human health, but because sunlight also creates vitamin D in human skin, the exact amount consumed by the body varies and follows an irregular pattern [35]. Vitamin D insufficiency causes bone deformity and weakening, making it essential for regular bodily function. Vitamin D insufficiency has been linked to a variety of illnesses, including osteoporosis, rickets, osteomalacia, loss of balance, diabetes, rheumatoid arthritis, asthma, depression, epilepsy, and a weakened immune system. Calcitriol is required for calcium homeostasis to be maintained. It also plays a role in the development of white blood cells, which are a key component of immune responses.

Vitamin E is made up of four types of tocopherols and tocotrienols that combine to generate eight naturally occurring forms of vitamin E: alpha, beta, gamma, and delta tocopherol and tocotrienol classes. The eight molecules are referred to as "tocochromanols" and are fat-soluble antioxidants. Alpha- and gamma-tocopherols are found in serum and red blood cells, with alpha-tocopherol having the highest concentration [24]. The antioxidant vitamin E protects the body's structures from oxidative damage. Low-density lipoproteins are protected against oxidative degradation by Vitamin E insufficiency.

Because the name "vitamin $\mathrm{K}$ " is derived from the German word "koagulation," which means "blood clotting," it is also known as "blood clotting factors." Vitamin $\mathrm{K}$ is divided into three types: K1 (phylloquinone), K2 (menaquinone), and K3 (phylloquinone) (Menadione). The $\mathrm{K} 1$ type is the most common and is required for photosynthesis in plants. The K2 type is derived from K1. Vitamin $\mathrm{K} 3$ is produced by bacteria and other microbes. The biological conversion of $\mathrm{K} 1$ and $\mathrm{K} 3$ in the human body produces K2. Although $\mathrm{K} 2$ is not found in plants, it is produced by bacteria through the transformation of K1 into K2 [44]. Vitamin K is required for blood coagulation and aids in the preservation of bone health by preventing demineralization [11]. 
Water-soluble vitamins include vitamins B1, B2, B3, B5, B6, B9, B12, biotin, and C. Vitamin B1 is also known as thiamin and is a member of the vitamin B complex. In human health, vitamin B1 is critical. It plays a role in converting carbs and lipids into energy. Vitamin B1 is a co-enzyme precursor for a number of essential carbohydrate metabolism enzymes [12]. It is also involved in the detoxification of alcohol [12], as well as the structural growth of brain cells.

Riboflavin is the name of vitamin B2. It has a role in the metabolic process of energy. Glutathione, the most important antioxidant that protects the body from free radicals, is recycled by vitamin B2. Iron deficiency raises the risk of anaemia because iron is required for the synthesis of red blood cells.

Niacin is another name for vitamin B3. Niacin is a category of chemicals possessing vitamin action. Nicotinic acid, nicotinamide, and a variety of enzymatic forms make up vitamin B3. Nicotinamide adenine dinucleotide (NAD) and nicotinamide adenine dinucleotide phosphate (NADP) are two types of vitamin B3 that are involved in the generation of energy from proteins, carbohydrates, and lipids in the diet. Free radical scavengers like NAD, NADP, and niacin-containing enzymes protect tissues from oxidative injury.

Pantothenic acid (Vitamin B5) is derived from the Greek term "pantothen," which means "from all sides" or "from all quarters." The name pantothenic acid comes from the fact that this vitamin is frequently found in foods. Pantothenic acid, which is incorporated into Coenzyme A (CoA), plays a critical role in energy metabolism.

Pyridoxal (PL), pyridoxine (PN), pyridoxal 5'-phosphate (PLP), pyridoxamine (PM), pyridoxine-5'-phosphate (PNP), and pyridoxamine 5'-phosphate (PMP) are the many forms of vitamin B6 [8]. Red blood cell synthesis, glucose metabolism, liver detoxification, and brain and nervous system function are all aided by vitamin B6.

Vitamin B9, also known as folate, is a water-soluble vitamin. It is vital to human health. Dihydrofolates, methyl folate, poly glutamyl folates, and mono glutamyl folates are all forms of flutes found in food [25]. In humans, vitamin B9 is important for brain health and supports the circulatory and nervous systems [25].

Cobalt is found in the structure of vitamin B12, often known as cobalamin [37]. This vitamin is required for energy metabolism and other biological activities, but it performs some roles that are distinct from those of the B complex vitamins [37]. Vitamin B12 may be kept in the body for a long time, although most other B vita- mins cannot. It also has a more complicated structure and a larger molecule. Vitamin B12 is synthesised by microorganisms such as bacteria and fungi, and it is difficult to absorb. Vitamin B12 is required for erythrocyte maturation during the generation of red blood cells as well as to maintain human cardiovascular health by avoiding an increase in homocysteine levels.

Biotin was originally known as coenzyme $\mathrm{R}$, vitamin $\mathrm{H}$, or vitamin B7, but it is now just called Biotin. Biotin is a B-complex vitamin that plays a key role in sugar and fat metabolism, among other things.

A frequently identified supplement is vitamin C (ascorbic acid) [20]. Vitamin C has antioxidant properties, which means it can preserve cellular structures from free radical damage. Its vast absorption in converting iron into a form that can be absorbed easily in the intestines. Vitamin $\mathrm{C}$ is necessary for the formation of collagen, a structural component of the human body. Vitamin $\mathrm{C}$ is also required for the manufacture of some neurotransmitters, particularly those involved in the transmission of feelings, ideas, and directions throughout the brain and nervous system.

\section{Antioxidant}

An antioxidant is a molecule that prevents other molecules from oxidising. Oxidation is a chemical reaction in which electrons are lost or the oxidation state is increased. Free radicals can be produced during oxidation reactions. Although oxidation reactions are necessary for life, they may also be harmful; plants and animals have complicated systems that include antioxidants like glutathione, vitamin $\mathrm{C}$, vitamin $\mathrm{A}$, and vitamin $\mathrm{E}$, as well as enzymes like catalase, superoxide dismutase, and different peroxidases. Oxidative stress is caused by a lack of antioxidants or inhibition of antioxidant enzymes, which can harm or kill cells [39].

An antioxidant is stable enough to give an electron to a rogue free radical, neutralising it and limiting the free radical's ability to cause damage. Because of their ability to scavenge free radicals, these antioxidants can postpone or prevent cellular damage. These low-molecular-weight antioxidants can safely interact with free radicals and stop the chain reaction from causing harm to critical components. Some antioxidants, such as glutathione, ubiquinol, and uric acid, are created by the body's natural metabolism. Dietary sources of lighter antioxidants can also be identified. Although the body has multiple enzyme systems that scavenge free radicals, vitamin E (-tocopherol), vitamin C (ascorbic acid), and B-carotene are the most important micronutrient (vitamin) antioxidants. Because the body cannot produce certain micronutrients, they must be obtained through the diet. 
Antioxidants function as radical scavengers, hydrogen donors, electron donors, peroxide decomposers, singlet oxygen quenchers, enzyme inhibitors, synergists, and metal chelating agents. To detoxify ROS, both enzymatic and nonenzymatic antioxidants exist in both the intracellular and extracellular environment [28].

\section{Types of antioxidant}

\section{Based on the of mechanism of antioxidant action}

Antioxidants are divided into three groups based on their mechanisms: (1) primary antioxidants, which act as free radical terminators (scavengers); (2) secondary antioxidants, which act as important preventive antioxidants by delaying chain initiation; and (3) tertiary antioxidants, which work to repair damaged biomolecules.

\section{Based on the solubility of antioxidants}

- Hydrophilic: They are water soluble which is react with oxidants in the cell cytosol and the blood plasma, like: Uric acid, Ascorbic acid (vitamin C), Glutathione and Lipoic acid.

- Lipophilic: They are soluble in lipids which can protect cell membranes from lipid peroxidation, like: Carotenes, $\alpha$-Tocopherol (vitamin E), Ubiquinol (coenzyme Q) and melatonine.

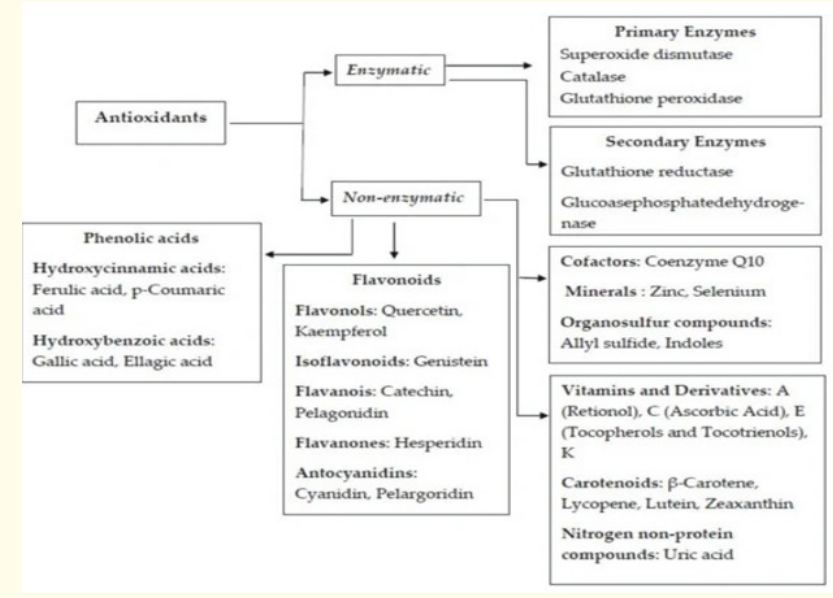

Figure 1: Types of Antioxidants.

https://www.sciencedirect.com/book/9780123756886/nutsand-seeds-in-health-and-disease-prevention [45,49].
Different techniques used to measure Antioxidant activity

Antioxidant activity should not be measured using a single approach. To assess antioxidant activity for the sample of interest, several antioxidant procedures should be done in vitro. The numerous methods for determining antioxidant capacity are divided into three categories: spectrometry, electrochemical assays, and chromatography.

Spectrometry

\begin{tabular}{|c|c|c|}
\hline $\begin{array}{l}\text { Antioxidant } \\
\text { capacity assay }\end{array}$ & Principle of the method & $\begin{array}{l}\text { End product } \\
\text { determination }\end{array}$ \\
\hline $\begin{array}{l}\text { Oxygen Radi- } \\
\text { cal Absorbance } \\
\text { Capacity }\end{array}$ & $\begin{array}{c}\text { Antioxidant reaction with } \\
\text { peroxyl radicals, stimu- } \\
\text { lated by } \\
\text { 2,2 0-azobis-2-amidino- } \\
\text { propane } \\
\text { (AAPH) }\end{array}$ & $\begin{array}{l}\text { Fluoresce in fluores- } \\
\text { cence decrease }\end{array}$ \\
\hline $\begin{array}{l}\text { Hydroxyl Radi- } \\
\text { cal Antioxidant } \\
\text { Capacity }\end{array}$ & $\begin{array}{c}\text { Antioxidant capacity to } \\
\text { quench OH radicals bring } \\
\text { out by a Co (II) based } \\
\text { Fenton-like system }\end{array}$ & $\begin{array}{l}\text { Fluoresce in fluores- } \\
\text { cence decrease }\end{array}$ \\
\hline $\begin{array}{l}\text { Total Peroxyl } \\
\text { Radical Trap- } \\
\text { ing Antioxidant } \\
\text { Parameter }\end{array}$ & $\begin{array}{c}\text { Antioxidant capacity to } \\
\text { scavenge } \\
\text { luminol-derived radicals, } \\
\text { Produced by the break- } \\
\text { down of AAPH }\end{array}$ & $\begin{array}{c}\text { Chemiluminescence } \\
\text { quenching }\end{array}$ \\
\hline $\begin{array}{l}\text { Cupric Reducing } \\
\text { Antioxidant Power }\end{array}$ & $\begin{array}{c}\text { Antioxidants reduce } \mathrm{Cu} \\
\text { (II) to } \mathrm{Cu}(\mathrm{I})\end{array}$ & Colorimetry \\
\hline $\begin{array}{c}\text { Ferric Reducing } \\
\text { Antioxidant Power }\end{array}$ & $\begin{array}{c}\text { Antioxidant react with } \\
\text { a Fe(III) complex }\end{array}$ & Colorimetry \\
\hline $\begin{array}{l}\text { Potassium fer- } \\
\text { ricyanide reducing } \\
\text { power }\end{array}$ & $\begin{array}{c}\text { Potassium ferricyanide } \\
\text { reduction by antioxidants } \\
\text { and subsequent reaction } \\
\text { of potassium ferrocyanide } \\
\text { with addition of Fe3+ }\end{array}$ & Colorimetry \\
\hline $\begin{array}{l}\text { 2,20-Azinobis-(3- } \\
\text { ethylbenzothia- } \\
\text { zoline-6-sulfonic } \\
\text { acid }\end{array}$ & $\begin{array}{c}\text { Antioxidant react with an } \\
\text { organic } \\
\text { cation radical }\end{array}$ & Colorimetry \\
\hline $\begin{array}{c}\text { 2,2-di(4-tert-octyl- } \\
\text { phenyl)- } \\
\text { 1-picrylhydrazyl] }\end{array}$ & $\begin{array}{c}\text { Antioxidant react with an } \\
\text { organic radical }\end{array}$ & Colorimetry \\
\hline
\end{tabular}

Table a 
Fluorimetric analysis

\begin{tabular}{|c|c|c|}
\hline $\begin{array}{c}\text { Antioxidant } \\
\text { capacity assay }\end{array}$ & $\begin{array}{c}\text { Principle of the } \\
\text { method }\end{array}$ & $\begin{array}{c}\text { End product } \\
\text { determination }\end{array}$ \\
\hline $\begin{array}{c}\text { Fluorimetric } \\
\text { Analysis }\end{array}$ & $\begin{array}{c}\text { Emission of light by a } \\
\text { compound, } \\
\text { which has absorbed } \\
\text { light or other }\end{array}$ & $\begin{array}{c}\text { By Recording of } \\
\text { fluorescence }\end{array}$ \\
& $\begin{array}{c}\text { electromagnetic } \\
\text { radiation of a differ- } \\
\text { ent wavelength or } \\
\text { frequency }\end{array}$ \\
\hline
\end{tabular}

Table b

Electrochemical techniques

\begin{tabular}{|c|c|c|}
\hline $\begin{array}{l}\text { Antioxidant } \\
\text { capacity assay }\end{array}$ & Principle of the method & $\begin{array}{l}\text { End product } \\
\text { determination }\end{array}$ \\
\hline Voltammetry & $\begin{array}{l}\text { The reduction or oxidation } \\
\text { of a compound at the surface } \\
\text { of a working electrode, at } \\
\text { the suitable applied poten- } \\
\text { tial, resulting in the mass } \\
\text { transport of new material on } \\
\text { the electrode surface and in } \\
\text { the generation of a current }\end{array}$ & $\begin{array}{l}\text { By Measurement of } \\
\text { the current of the } \\
\text { cathodic/anodic } \\
\text { peak }\end{array}$ \\
\hline Amperometry & $\begin{array}{c}\text { The potential of the working } \\
\text { electrode is set at a fixed } \\
\text { value in the comparison to a } \\
\text { reference electrode }\end{array}$ & $\begin{array}{c}\text { Measurement of the } \\
\text { current produced } \\
\text { by the oxidation/re- } \\
\text { duction of an elec- } \\
\text { troactive analyte }\end{array}$ \\
\hline Biamperometry & $\begin{array}{l}\text { The reaction of the analyte } \\
\text { (antioxidant) with the oxi- } \\
\text { dised form of } \\
\text { a reversible Showing the } \\
\text { presence of redox couple }\end{array}$ & $\begin{array}{c}\text { Measurement of the } \\
\text { current flowing } \\
\text { between two } \\
\text { identical working } \\
\text { electrodes, at a low } \\
\text { voltage difference } \\
\text { and immersed in a } \\
\text { solution containing } \\
\text { the analysed sample } \\
\text { and a reversible } \\
\text { redox couple }\end{array}$ \\
\hline
\end{tabular}

Table c
Chromatography analysis

\begin{tabular}{|c|c|c|}
\hline $\begin{array}{l}\text { Antioxidant } \\
\text { capacity assay }\end{array}$ & Principle of the method & $\begin{array}{c}\text { End product } \\
\text { determination }\end{array}$ \\
\hline $\begin{array}{c}\text { Gas } \\
\text { chromatography }\end{array}$ & $\begin{array}{l}\text { Separation of the com- } \\
\text { pounds in a mixture is } \\
\text { depend on the reparti- } \\
\text { tion between a liquid } \\
\text { stationary phase and a } \\
\text { gas mobile phase }\end{array}$ & $\begin{array}{c}\text { By Flame ionisation } \\
\text { or thermal conduc- } \\
\text { tivity detection }\end{array}$ \\
\hline $\begin{array}{c}\text { High performance } \\
\text { liquid } \\
\text { chromatography }\end{array}$ & $\begin{array}{c}\text { Separation of the com- } \\
\text { pounds in } \\
\text { a mixture is depend on } \\
\text { the repartition between } \\
\text { a solid stationary phase } \\
\text { and a liquid mobile phase } \\
\text { with different polarities, } \\
\text { at high flow rate and } \\
\text { pressure of the mobile } \\
\text { phase }\end{array}$ & $\begin{array}{l}\text { By UV-Vis (e.g., } \\
\text { diode array) detec- } \\
\text { tion, fluorimetric } \\
\text { detection, mass } \\
\text { spectrometry or } \\
\text { electrochemical } \\
\text { detection }\end{array}$ \\
\hline
\end{tabular}

Table d

\section{Vitamins as an antioxidant}

Water-soluble vitamins as an antioxidant

\section{Vitamin B1 (Thiamine)}

Vitamin B1 has a role in the creation of energy from carbohydrates and lipids. Thiamine functions as a co-enzyme precursor for a number of key carbohydrate metabolism enzymes [12]. It is also involved in the detoxification of alcohol [12] and aids in the structural growth of brain cells.

\section{Vitamin B2 (Riboflavin)}

Vitamin B2 is a part of energy metabolism and antioxidant protection [29]. Riboflavin is one of the most underappreciated antioxidant nutrients, while vitamin $\mathrm{C}$, E, and carotenoids are the most well-known antioxidants. Because of the glutathione redox cycle and its conversion from reduced to oxidised riboflavin, riboflavin has some antioxidant properties that protects the body from free radicals [10]. It also aids iron metabolism, and a lack of it raises the risk of anaemia because iron is required for red blood cell synthesis. In its FAD (Flavin Adenine dinucleotide) and FMN (Flavin Mononucleotide) forms, riboflavin serves as a coenzyme for redox 
enzymes. Because FAD coenzyme is required for glutathione reductase activity in converting oxidised glutathione to its reduced form [29], they operate as antioxidants in this state. During its conversion to its oxidised form, reduced glutathione works as an antioxidant in the intracellular environment by neutralising reactive oxygen species. FAD had to convert the oxidised glutathione back to its reduced form in order to restore its antioxidant properties. Its ability to deactivate peroxides, particularly hydroperoxides, is dependent on glutathione [40]. As a result, riboflavin shortage is thought to enhance lipid peroxidation. Several animal investigations found that riboflavin shortage had deleterious effects on lipid metabolism as well as the desired impact of riboflavin treatment $[15,43]$.

Vitamin B3 (Niacin/nicotinamide adenine dinucleotide (NAD) and nicotinamide adenine dinucleotide phosphate (NADP)

They are largely responsible for converting dietary proteins, carbohydrates, and lipids into energy. In its Nicotinamide Adenine Dinucleotide (NAD) and Nicotinamide Mononucleotide (NMN) forms, niacin (vitamin B3) works as a coenzyme for redox enzymes. Free radical scavengers NAD, NADP, and niacin-containing enzymes protect tissues from oxidative stress. A research investigating the potentially beneficial effect of Niacin administration in rats exposed to methyl mercury found that niacin reduced the negative effects of methyl mercury, and the mechanism behind this was considered to be related to Niacin's intrinsic antioxidant potential [9]. In invitro experiments on glycated human serum albumin, niacin lowered glycation and reduced DNA damage [2]. In alloxan-induced diabetic rats, niacin was found to reduce lipid peroxidation, protein carbonylation, DNA damage, and tissue injury caused by reactive oxygen species [1].

\section{Vitamin B5 (Pantothenic acid)}

Pantothenic acid (PA), also known as vitamin B5, is a watersoluble vitamin that is a component of coenzyme A (CoA), which is involved in several intermediary metabolic reactions involving glucose, fatty acids, and amino acids, such as the tricarboxylic acid cycle, acetylation of choline to form acetylcholine, and fatty acid biosynthesis. In gamma-irradiated rats, pantothenic acid administration was found to greatly reduce oxidative stress and alleviate brain damage.

\section{Vitamin B6 (Pyridoxine)}

ViPyridoxine is a water-soluble B vitamin that is required for protein, lipid, carbohydrate metabolism [8]. Pyridoxine, despite not being a traditional antioxidant, has some antioxidant properties. It's also involved in the brain and nervous system's neurotransmitter manufacturing [19]. Pyridoxine works as an active hydroxyl radical $(-\mathrm{OH})$ scavenger, able to sweep up to eight $-\mathrm{OH}$ molecules, according to the study [42]. Vitamin B6 deficient rats suffered peroxidative stress due to increased thiobarbituric acid activity in the rat liver and heart [18], implying that pyridoxine plays a key role in preventing peroxidation. Vitamin B6 aids in liver detoxification, and a lack of it causes liver malfunction [38]. Pyridoxine reacts more strongly with hydroxyl radicals through binding with the pyridoxine aromatic ring or abstraction of hydrogen from the groups attached to the ring, according to a theoretical study of the scavenging capacity of pyridoxine on different reactive oxygen species, such as hydroxyl, superoxide, and oxygen radical. A lack of vitamin B6 has been associated to attention deficit disorder.

\section{Vitamin B9 (Folate)}

Vitamin B9, also known as Folates, comes in three reduced forms: 7, 8-dihydrofolate (DHF), 5, 6, 7, 8-tetrahydrofolate (THF), and 5-methyltetrahydrofolate (5-MTHF). The antioxidant properties of reduced forms of folic acid were found to be comparable to those of vitamin C and vitamin E [34]. Folates, on the other hand, may have a direct antioxidant impact in vivo that is unrelated to its homocysteine-lowering effect. They are important vitamins for cardiovascular health because of their ability to lower plasma homocysteine levels [17]. Folate has also been shown to help with haematological disease, cancer $[4,27,33]$, neurological problems [6], and neural tube malformations [26] in multiple trials. THF has the best anti-lipid peroxidation properties, while DHT is particularly effective against ABTS+ cations. The antioxidant property of folates has been hypothesised to play a preventive function in various illnesses.

\section{Vitamin B12 (Cobalamine)}

Vitamin B12, commonly known as cobalamin, is a water-soluble vitamin that is necessary for brain health and hemotopoiesis. Vitamin B12 also helps to keep bones healthy, as a lack of this vitamin increases the risk of osteoporosis. Some data from in-vitro experiments suggests that cobalamin may have antioxidant activity. Some 
Researchers believe vitamin B12 has a direct superoxide scavenger mechanism [21]. The quantity of superoxide in the intracellular fluid and mitochondrion was reduced after cyanocobalamin was given to human aortic cells. Cell-free systems and neuronal cells found similar results. Vitamin B12 promotes homocysteine conversion to methionine, hence a vitamin B12 deficit will result in higher homocysteine levels [37]. Homocysteine is easily converted to hydrogen peroxide, which increases the amount of reactive oxygen species in the body. As a result of its function in homocysteine metabolism, it protects against oxidative stress indirectly. Vitamin B12 may be important in the oxidative stress cycle. Vitamin B12's capacity to retain glutathione is also linked to its antioxidant properties. The responses implicated in this, however, are being investigated. Advanced glycated end products can be formed as a result of oxidative stress, which can diminish vitamin B12 intake.

\section{Vitamin C (Ascorbic acid)}

Vitamin C is widely known for its antioxidant qualities, which help to protect cellular structures from free radical damage. Both animals and plants have vitamin $\mathrm{C}$, which is a monosaccharide oxidation-reduction (redox) catalyst. Ascorbic acid is a redox catalyst that can reduce reactive oxygen species like hydrogen peroxide and thereby neutralise them.Vitamin $C$ is an essential component for the human body. This helps to control lipid peroxidation of cellular membranes and nuclear materials. Aside from its direct antioxidant properties, ascorbic acid is a substrate for the redox enzyme ascorbate peroxidase, which plays a key role in plant stress tolerance [13]. Due to its antioxidant and anti-inflammatory properties, vitamin $C$ in conjunction with L-carnitine has been shown to ameliorate cisplatin-induced nephrotoxicity [5]. Conversely, Vitamin C can behave as a pro-oxidant in certain conditions. It has also been reported to generate ascorbate radicals and Hydrogen peroxide in pharmacological doses [22]. Vitamin C, on the other hand, can act as a pro-oxidant under certain circumstances. High-dose vitamin $\mathrm{C}$ has been shown to cause mitochondrial membrane potential disruption and promote ROS generation inside cells. Therefore, Ascorbic acid in high doses has been suggested to kill cancer cells by inducing pro-oxidant effects selectively. In therapeutic levels, vitamin $\mathrm{C}$ has also been shown to produce ascorbate radicals and hydrogen peroxide [22]. Ascorbic acid, in high quantities, has been proposed to destroy cancer cells by specifically triggering pro-oxidant effects. The production of hydrogen peroxide in cells and the depletion of
Nicotinamide Adenine Dinucleotide are two mechanisms proposed for its anti-cancer activity.

\section{Fat-soluble vitamins as an antioxidant} Vitamin D (Calciferol)

Vitamin D is a fat-soluble vitamin that includes Vitamin D3 (cholecalciferol) and Vitamin D2 (ergocalciferol). Many health experts have termed Vitamin D the "miracle vitamin" due to mounting evidence of its importance in promoting health and overcoming diseases such as cancer, heart disease, and diabetes. Vitamin D supplementation for nine weeks has positive effects on oxidative stress biomarkers in pregnant women. It increased total antioxidant capacity and glutathione activity, as well as the activity of other metabolic enzymes. Calcitriol, for example, has been shown to behave similarly to classical antioxidant supplements by blocking an enzyme called inducible nitric oxide synthase (iNOS), which is overactive in Alzheimer's and Parkinson's disease patients [30]. The evidence in the literature suggests that Vitamin D3 has a significant antioxidant role in mature erythrocytes without a nucleus. This result not only confirms that cholecalciferol has an antioxidant effect, but also suggests that 1,25-dihydroxycholecalciferol may act as a direct antioxidant of the membrane by stabilising and protecting the membrane from lipid peroxidation via its hydrophobic parts. Vitamin D supplement has been shown to protect people with diabetes from oxidative stress-related vascular problems.

\section{Vitamin E (Tocopherol)}

Tocopherols and tocotrienols are both included in the vitamin E group of chemicals. Vitamin $\mathrm{E}$ is found in eight different chemical forms in nature (alpha-, beta-, gamma-, and delta-tocopherol and alpha-, beta-, gamma-, and delta-tocotrienol), as a fat-soluble vitamins each with a different level of biological activity.Vitamin $\mathrm{E}$ has been studied for nearly a century, along with its physiological roles and anti-oxidative properties. It's the umbrella term for a collection of fat-soluble chemicals with different antioxidant properties. Among the vitamin E compounds with antioxidant properties, alpha-tocopherol has gained the most attention, although recent research suggests that tocotrienols may have different health-promoting properties. Vitamin E works as a peroxyl radical scavenger in tissues, preventing the formation of harmful free radicals by interacting with them to generate a tocopheryl radical, which is then reduced by a hydrogen donor (such as vitamin $\mathrm{C}$ ) and therefore returns to its reduced state. In exercise-induced oxidative stress, a 
higher concentration of alpha-tocopherol in the liver was observed to protect against oxidative damage [36]. In addition, alpha-tocopherol has been shown to diminish oxidative stress in lead-exposed workers, and alpha-tocopherol injection restored the negative health effects of lead exposure that caused oxidative stress.

\section{Vitamin K (Phytonadione)}

Vitamin $\mathrm{K}$ is a fat-soluble molecule that plays an important function in mammalian physiology. K1 (Phylloquinone), K2 (Menaquinone), and K3 (Menadione) are the three types of vitamin K. Its principal purpose is to aid in the coagulation of blood. It could be a crucial anti-aging vitamin. It has the potential to protect against both heart disease and osteoporosis. Vitamin K1 (Phylloquinone) is produced by leafy plants. Vitamin K2 (Menaquinone), on the other hand, is a product of gut bacteria or the conversion of phylloquinone from the diet. As a result, in animal tissues, menaquinone isp. Furthermore, vitamin $\mathrm{K}$ hydroquinone (KH2) was a robust biological antioxidant, but there is a paucity of information on the regeneration antioxidative enzymatic processes for this essential trace nutrient, which might be a research topic. Vitamin K could be the key to treating certain cancers in the future. It's also possible that it has something to do with Alzheimer's disease.

\section{Vitamin A (Retinol/Retinoic acid)}

Vitamin A, commonly known as retinoic acid, has the ability to prevent viral hepatitis. Despite the fact that vitamin A is not a wellknown antioxidant, a few studies have suggested that it may play an indirect antioxidant role. Carotenes (beta and alpha carotene) are the precursors to Vitamin A and are found in plant sources. Many forms of carotenes, such as alpha and beta carotene, and lycopene, are powerful antioxidants And carotenes have two purposes in the human body: they can be converted to Vitamin A or they can be used as an antioxidant. Furthermore, in both healthy and varicocele sperm, all-trans retinoic acid increased superoxide dismutase and glutathione transferase activity while decreasing malondialdehyde and reactive oxygen species, implying that retinol increases antioxidant enzyme activity. The singlet oxygen free radical is especially attacked by carotenoids. About $40 \%$ of carotenes are converted to Vitamin A, while $60 \%$ serve as potent antioxidants, which is beneficial because your body will only convert carotenes to Vitamin A if it is required. The rest will circulate as antioxidants in your bloodstream. As a result, there is mounting evidence that vitamin A may help protect the body from the effects of oxidative stress.
One subheading namely Health consequences specific to disease progression: It must be addressed.

\section{Conclusion}

Many chronic health problems, such as cardiac and inflammatory diseases, cataracts, and cancer, are linked to free radical damage. Antioxidants protect tissue from free radical damage by inhibiting radical production, scavenging radicals, or encouraging their breakdown. Synthetic antioxidants (give some example of synthetic antioxidant) have lately been linked to health risks in humans. As a result, in recent years, the hunt for efficacious, harmless natural substances with antioxidative action has intensified. Studies on the antioxidant properties of vitamins are discussed in this overview. Apart from classical antioxidants (Vitamin C, E, and carotenoids), it has also been able to draw attention to other vitamins (Vitamin $\mathrm{K}$, Vitamin D, Niacin, Pyridoxine, and Riboflavin) that play important roles in defending the body against free radicals by potentiating enzyme antioxidants, acting as co-enzymes in their reduced physiological forms, or directly attacking free radicals.

\section{Acknowledgments}

We are grateful to Rathod Zalak for his guidance to prepare the manuscript. I gratitude to Prof. Meenu Saraf, DIST-FIST HOD of Department of Microbiology and Biotechnology, School of sciences, Gujarat university for her continuous support.

\section{Competing Interests}

The authors declare that there is no conflict of interests.

\section{Bibliography}

1. Abdullah K M., et al. "Therapeutic effect of vitamin B3 on hyperglycemia, oxidative stress and DNA damage in alloxan induced diabetic rat model". Biomedicine and Pharmacotherapy 105 (2018): 1223-1231.

2. Abdullah K M., et al. "Inhibitory effect of vitamin B3 against glycation and reactive oxygen species production in HSA: An in vitro approach". Archives of Biochemistry and Biophysics 627 (2017): 21-29.

3. Agarwal A., et al. "Role of oxidative stress in female reproduction". Reproductive Biology and Endocrinology 3.1 (2005): 1-21. 
4. Akoglu B., et al. "Folate and chemoprevention of colorectal cancer: Is 5-methyl-tetrahydrofolate an active antiproliferative agent in folate-treated colon-cancer cells?". Nutrition (Burbank, Los Angeles County, Calif.) 17.7-8 (2001): 652-653.

5. Alabi Q K., et al. "Combined administration of L-carnitine and ascorbic acid ameliorates cisplatin-induced nephrotoxicity in rats". Journal of the American College of Nutrition 37.5 (2018): 387-398.

6. Alpert JE and Fava M. "Nutrition and depression: the role of folate". Nutrition Reviews 55.5 (1997): 145-149.

7. Al-Shawi S G., et al. "Study of cumin antibacterial and antioxidant activity of alcoholic and aqueous extracts". Pakistan Journal of Biotechnology 14.2 (2017): 227-231.

8. Angel J F. "Gluconeogenesis in meal-fed, vitamin B-6-deficient rats". The Journal of Nutrition 110.2 (1980): 262-269.

9. Anugu S., et al. "Effect of vitamin E on the immune system of ewes during late pregnancy and lactation". Small Ruminant Research 111.1-3 (2013): 83-89.

10. Ashoori M and Saedisomeolia A. "Riboflavin (vitamin B2) and oxidative stress: a review”. British Journal of Nutrition 111.11 (2014): 1985-1991.

11. Atkins G J., et al. "Vitamin $\mathrm{K}$ promotes mineralization, osteoblast-to-osteocyte transition, and an anticatabolic phenotype by $\gamma$-carboxylation-dependent and-independent mechanisms". American Journal of Physiology-Cell Physiology 297.6 (2009): C1358-C1367.

12. Bâ A. "Metabolic and structural role of thiamine in nervous tissues”. Cellular and Molecular Neurobiology 28.7 (2008): 923.

13. Baillie J K., et al. "Oral antioxidant supplementation does not prevent acute mountain sickness: double blind, randomized placebo-controlled trial". QJM: An International Journal of Medicine 102.5 (2009): 341-348.

14. Bansal A K and Bilaspuri G S. "Impacts of oxidative stress and antioxidants on semen functions". Veterinary Medicine International (2011).
15. Bates C J. "Glutathione and related indices in rat lenses, liver and red cells during riboflavin deficiency and its correction". Experimental Eye Research 53.1 (1991): 123-130.

16. Belenchia A M., et al. "Correcting vitamin D insufficiency improves insulin sensitivity in obese adolescents: a randomized controlled trial". The American Journal of Clinical Nutrition 97.4 (2013): 774-781.

17. Boushey C J., et al. "A quantitative assessment of plasma homocysteine as a risk factor for vascular disease: probable benefits of increasing folic acid intakes". Jama 274.13 (1995): 1049-1057.

18. Cabrini L., et al. "Vitamin B6 deficiency affects antioxidant defences in rat liver and heart". IUBMB Life 46.4 (1998): 689-697.

19. Ceriello A., et al. "Is oxidative stress the pathogenic mechanism underlying insulin resistance, diabetes, and cardiovascular disease? The common soil hypothesis revisited". Arteriosclerosis, Thrombosis, and Vascular Biology, 24.5 (2004): 816-823.

20. Chambial S., et al. "Vitamin C in disease prevention and cure: an overview". Indian Journal of Clinical Biochemistry 28.4 (2013): 314-328.

21. Chan W., et al. "Cobalamin-associated superoxide scavenging in neuronal cells is a potential mechanism for vitamin B12-deprivation optic neuropathy". The American Journal of Pathology 188.1 (2018): 160-172.

22. Chen Q., et al. "Ascorbate in pharmacologic concentrations selectively generates ascorbate radical and hydrogen peroxide in extracellular fluid in vivo". Proceedings of the National Academy of Sciences 104.21 (2001): 8749-8754.

23. Cho N E., et al. "Retinoid regulation of antiviral innate immunity in hepatocytes". Hepatology 63.6 (2016): 1783-1795.

24. Chow C K. "Distribution of tocopherols in human plasma and red blood cells". The American Journal of Clinical Nutrition 28.7 (1972): 756-760.

25. Crider K S., et al. "Folic acid food fortification-its history, effect, concerns, and future directions". Nutrients 3.3 (2011): 370-384. 
26. Daly L E., et al. "Folate levels and neural tube defects: implications for prevention". Jama 274.21 (1995): 1698-1702.

27. Duthie S J., et al. "Impact of folate deficiency on DNA stability". The Journal of nutrition 132.8 (2002): 2444S-2449S.

28. Frei B., et al. "Antioxidant defenses and lipid peroxidation in human blood plasma". Proceedings of the National Academy of Sciences 85.24 (1988): 9748-9752.

29. Gallagher ML. "Intake: the nutrients and their metabolisms". In Eds.: Mahan LK, Escott-Stump S, Raymond JL, et al. Krause's Food and the Nutrition Care Process, $\left(13^{\text {th }}\right.$ Edn.). St Louis, MO: Elsevier/Saunders (2012): 32-128.

30. Garcion E., et al. "1, 25-Dihydroxyvitamin D3 inhibits the expression of inducible nitric oxide synthase in rat central nervous system during experimental allergic encephalomyelitis". Molecular Brain Research 45.2 (1997): 255-267.

31. German J B. "Food processing and lipid oxidation". Impact of Processing on Food Safety (1999): 23-50.

32. Giles G I and Jacob C. "Reactive sulfur species: an emerging concept in oxidative stress" (2002).

33. Giovannucci, E. "Epidemiologic studies of folate and colorectal neoplasia: a review". The Journal of Nutrition 132.8 (2002): 2350S-2355S.

34. Gliszczyńska-Świgło A. "Folates as antioxidants". Food Chemistry 101.4 (2007): 1480-1483.

35. Gombart A F. "The vitamin D-antimicrobial peptide pathway and its role in protection against infection". Future Microbiology 4.9 (2009): 1151-1165.

36. Górnicka M., et al. "Alpha-Tocopherol May Protect Hepatocytes Against Oxidative Damage Induced by Endurance Training in Growing Organisms". Advances in Clinical and Experimental Medicine: Official organ Wroclaw Medical University 25.4 (2016): 673-679.

37. Green R., et al. "Vitamin B 12 deficiency". Nature Reviews Disease Primers 3.1 (2017): 1-20.
38. Gregory III., et al. "Metabolomic analysis reveals extended metabolic consequences of marginal vitamin B-6 deficiency in healthy human subjects". PloS One 8.6 (2013): e63544.

39. Halliwell B and Gutteridge JM. "The definition and measurement of antioxidants in biological systems". Free Radical Biology and Medicine 18.1 (1995): 125-126.

40. Hayes J D and McLELLAN L I. "Glutathione and glutathione-dependent enzymes represent a co-ordinately regulated defence against oxidative stress". Free Radical Research 31.4 (1999): 273-300.

41. Heitzer T., et al. "Endothelial dysfunction, oxidative stress, and risk of cardiovascular events in patients with coronary artery disease". Circulation 104.22 (2001): 2673-2678.

42. Higashi-Okai K., et al. "Antioxidant and prooxidant activities of B group vitamins in lipid peroxidation". Journal of UOEH 28.4 (2006): 359-368.

43. Hirano H., et al. "Effects of B2-deficiency on lipoperoxide and its scavenging system in the rat lens". International Journal for Vitamin and Nutrition Research. Internationale Zeitschrift fur Vitamin-und Ernahrungsforschung. Journal International de Vitaminologie et de Nutrition 53.4 (1983): 377-382.

44. Hirota Y., et al. "Menadione (vitamin K3) is a catabolic product of oral phylloquinone (vitamin K1) in the intestine and a circulating precursor of tissue menaquinone-4 (vitamin K2) in rats". Journal of Biological Chemistry 288.46 (2013): 3307133080.

45. https://www.sciencedirect.com/book/9780123756886/ nuts-and-seeds-in-health-and-disease-prevention

46. Ibrahim K S and El-Sayed E M. "Potential role of nutrients on immunity”. International Food Research Journal 23.2 (2016).

47. Incalza MA., et al. "Oxidative stress and reactive oxygen species in endothelial dysfunction associated with cardiovascular and metabolic diseases". Vascular Pharmacology 100 (2018): 1-19. 
48. Moharram H A and Youssef M M. "Methods for determining the antioxidant activity: a review". Alexandria Journal of Food Science and Technology 11.1 (2014): 31-42.

49. Sies H. "Oxidative stress: oxidants and antioxidants". Experimental Physiology: Translation and Integration 82.2 (1997):

291-295.

\section{Assets from publication with us}

- Prompt Acknowledgement after receiving the article

- Thorough Double blinded peer review

- Rapid Publication

- Issue of Publication Certificate

- High visibility of your Published work

Website: www.actascientific.com/

Submit Article: www.actascientific.com/submission.php

Email us: editor@actascientific.com

Contact us: +919182824667 